\title{
Beta-adrenergic receptor polymorphisms: A basis for pharmacogenetics
}

\author{
Efstratios K. Theofilogiannakos ${ }^{1 *}$, Konstantinos Dean Boudoulas ${ }^{2 *}$, Brian E. Gawronski ${ }^{3}$, \\ Taimour Y. Langaee ${ }^{3}$, Timotheos G. Kelpis ${ }^{1}$, Antonios A. Pitsis ${ }^{1}$, Julie A. Johnson ${ }^{3}$, \\ Harisios Boudoulas ${ }^{2,4 \#}$ \\ ${ }^{1}$ Agios Lukas Hospital, Thessaloniki, Greece \\ ${ }^{2}$ The Ohio State University, Division of Cardiovascular Medicine, Columbus, Ohio, USA \\ ${ }^{3}$ University of Florida, Department of Pharmacotherapy and Translational Research and Center for Pharmacogenomics, Gainesville, \\ Florida, USA \\ ${ }^{4}$ Aristotelian University of Thessaloniki, Thessaloniki, Greece \\ Email: "boudoulas@bioacademy.gr
}

Received 28 May 2013; revised 1 July 2013; accepted 16 July 2013

Copyright (C) 2013 Efstratios K. Theofilogiannakos et al. This is an open access article distributed under the Creative Commons Attribution License, which permits unrestricted use, distribution, and reproduction in any medium, provided the original work is properly cited.

\begin{abstract}
Aims: Polymorphisms of the $\beta$-adrenergic receptor, the frequency of which may differ in ethnic groups, alters $\beta$-receptor function. The aim of this study was to elucidate the frequency of $\beta_{1}$ and $\beta_{2}$-adrenergic receptor polymorphisms in healthy Greeks and to compare with those of Caucasian European (Euro) and African American (AA) origin. Methods: Ninetynine individuals with a median age of 63 without clinical evidence of any disease were studied. Blood samples were obtained and common $\beta_{1}$ and $\beta_{2}$-adrenergic receptor polymorphisms that change the encoded amino acid were determined by pyrosequencing. Results: The most common $\beta_{1}$-adrenergic receptor polymorphism in Greeks is nucleotide substitution cytosine for guanine at position $1165(1165 C / G)$ resulting in amino acid substitution arginine for glycine at position $389(389 \mathrm{Arg} / \mathrm{Gly})$ with a minor allele frequency of $28 \%$ (Euro $27 \%$, AA $42 \%$ ); this polymorphism increases the sensitivity of the $\beta_{1}$-receptor. The most common $\boldsymbol{\beta}_{2}$-adrenergic receptor polymorphism in Greeks is the nucleotide substitution guanine for adenine at position $46(46 G / A)$ resulting in amino acid substitution glycine for arginine at position $16(16 \mathrm{Gly} / \mathrm{Arg})$ with a minor allele frequency of $38 \%$ (Euro $41 \%$, AA 50\%); this polymerphism facilitates receptor down-regulation during chronic adrenergic stimulation. Conclusion: The most common $\beta_{1}$ and $\beta_{2}$-adrenergic receptor polymorphisms in the
\end{abstract}

\footnotetext{
*First and second authors contributed equally to the paper and are both equally first authors.

\#Corresponding author.
}

Greek population are similar to those of other European ancestry, and less common than in those of African origin indicating variability in ethnic groups. This information provides insight into common polymorphisms that may assist in optimizing $\beta$-antagonist and agonist therapy.

Keywords: $\beta_{1}$ and $\beta_{2}$-Adrenergic Receptor; Polymorphism; Ethnic Variability

\section{INTRODUCTION}

Normal function of $\beta$-adrenergic receptors plays an important role for cardiovascular and neurohumoral homeostasis in humans. Heart rate, arterial pressure, myocardial contractility, glucose metabolism and other vital functions are directly related to the function of $\beta$-adrenergic receptors, which are stimulated by secreted catecholamines. High adrenergic activity in certain disease states (i.e. heart failure, atrial fibrillation, neurocardiogenic syncope, other) may be deleterious. The pathophysiologic significance of $\beta$-adrenergic receptors and the effect of their blockade have been studied extensively for almost a century. Further, extrinsic stimulation or blockade of $\beta$-adrenergic receptors have been used for decades for the management of certain diseases such as heart failure, arterial hypertension, coronary artery disease, atrial fibrillation and others [1].

Polymorphisms of $\beta$-adrenergic receptors ( $\beta_{1}$-receptor and $\beta_{2}$-receptor) have been reported that alter the function of the receptor [2-5]. Thus, determination of $\beta$ adrenergic receptor polymorphisms is important to better 
understand their response to secreted catecholamines during daily activities. In addition, identifying polymorphisms may assist in optimizing management of patients where $\beta$-adrenergic stimulation or blockade therapy is used. Polymorphisms of $\beta$-adrenergic receptors have been studied in individuals of Caucasian European and African American origin [2]. Studies related to the frequency of $\beta_{2}$-receptor polymorphisms in the Greek population with pulmonary disease have also been reported [6]; however, the frequency of $\beta_{1}$ and $\beta_{2}$-adrenergic receptor polymorphisms in a healthy Greek population has not been studied. The present investigation was undertaken to elucidate the frequency of $\beta_{1}$ and $\beta_{2}$-adrenergic receptor polymorphisms in healthy Greeks and to compare this frequency with those of Caucasian European and African American origin in order to determine if the variability exists in different ethnic groups.

\section{METHODS}

\subsection{Study Population}

Ninety-nine individuals (70 male) with a median age of 63 years (range 31 to 80 years) without clinical evidence of disease were studied; medical history and physical examination were performed in order to exclude underlying disease in all studied individuals. All study participants were hospital employees of Agios Loukas Hospital, Thessaloniki, Greece, or volunteers that were non-blood relatives. Whole blood was obtained from each subject using standard venous puncture in which $10 \mathrm{~mL}$ of blood was collected into EDTA anti-coagulant tubes in order to determine $\beta$-adrenergic receptor polymorphisms. The study was approved by the Institutional Review Board of Agios Loukas Hospital and written informed consent was obtained by all participants.

\subsection{Determination of $\beta$-Adrenergic Receptor Polymorphisms}

Genomic DNA was isolated from lymphocytes in whole blood using a commercially available kit (Qiagen DNA Blood Isolation Kit, Qiagen, Valencia, California, USA). DNA samples were genotyped for two $\beta_{1}$-adrenergic receptors (ADRB1) including: 49 Ser/Gly (amino acid substitution of serine for glycine at position 49 resulting in the nucleotide substitution of adenine for guanine at position 145 (145 A/G), rs1801252); and $389 \mathrm{Arg} / \mathrm{Gly}$ (amino acid substitution of arginine for glycine at position 389 resulting in the nucleotide substitution of cytosine for guanine at position 1165 (1165 $C / G)$, rs1801253). In addition, DNA samples were genotyped for two $\beta_{2^{-}}$ adrenergic receptors (ADRB2) including: 16 Gly/Arg (amino acid substitution of glycine for arginine at position 16 resulting in the nucleotide substitution of guanine for adenine at position 46 (46 G/A), rs1042713); and 27
Gln/Glu (amino acid substitution of glutamine for glutamic acid at position 27 resulting in the nucleotide substitution of cytosine for guanine at position $79(79 \mathrm{C} / \mathrm{G})$, rs1042714). Single-nucleotide polymorphisms (SNPs) were determined by polymerase chain reaction (PCR) followed by pyrosequencing using a PSQ HS96A SNP reagent kit according to the manufacturer protocol (Biotage AB, Uppsala, Sweden) and TaqMan allelic discrimination (Applied Biosystems, Foster City, California, USA). The PCR primers and probes for ADRB1 $49 \mathrm{Ser} /$ Gly and 389 Arg/Gly (IDs C__8898508_10 and C 8898494_10), and ADRB2 16 Gly/Arg and $27 \mathrm{Gln} / \mathrm{Glu}$ (IDs C__2084764_20 and C__2084765_20) used in assays were purchased from Applied Biosystems (Applied Biosystems, Foster City, California, USA); $5 \mathrm{~mL}$ reactions in a 384-well plate were prepared and the assays were performed and analyzed according to the manufacturer's recommendations. The PCR and pyrosequencing primers for above-mentioned SNPs have been previously reported [7]. Genotype accuracy was verified by genotyping 5\% - 10\% randomly selected duplicate samples for each SNP on the alternate platform. The minor allele frequency was determined by allele counting, where each person has two alleles; the frequency of the least common allele is determined by: minor allele frequency $(\mathrm{MAF})=(\#$ heterozygous individuals $+2 * \#$ homozygous variant individuals)/2* total number of individuals in the study.

\section{RESULTS}

Frequencies of the $\beta$-adrenergic receptor genotypes $(\beta 1$ receptor and $\beta 2$-receptor) in the Greek population are shown in Table 1. Table 2 displays minor allele frequencies in Greeks, compared to population values for Caucasian Europeans and African Americans.

\subsection{Most Common $\beta_{1}$-Receptor Polymorphisms}

The most common $\beta_{1}$-receptor polymorphism found in the Greek population is a substitution of cytosine for guanine at position $1165(1165 C / G)$ that results in the amino acid substitution of arginine for glycine at position 389 (389 Arg/Gly); the minor allele frequency for this polymorphism is $28 \%$ in the Greek population. This polymorphism increases the sensitivity of the $\beta_{1}$-receptor during adrenergic stimulation [1-3].

The second most common $\beta_{1}$-receptor polymorphism found in the Greek population is a substitution of adenine for guanine at position $145(145 \mathrm{~A} / G)$ that results in the amino acid substitution of serine for glycine at position 49 (49 Ser/Gly); the minor allele frequency for this polymorphism is $10 \%$ in the Greek population. This polymorphism does not alter the sensitivity of the $\beta_{1}$ receptor during acute adrenergic stimulation, but may 
facilitate the down-regulation of the receptor during chronic adrenergic stimulation [2,3].

A rare third $\beta_{1}$-receptor polymorphism that has been previously reported, substitution of guanine for thymine at position $1666(1666 \mathrm{G} / \mathrm{T})$ that results in the amino acid substitution of arginine for leucine at position 389 (389 $\mathrm{Arg} / \mathrm{Leu}$ ), was not seen in our population.

\subsection{Most Common $\boldsymbol{\beta}_{2}$-Receptor Polymorphisms}

The most common $\beta_{2}$-receptor polymorphism found in the Greek population is a substitution of guanine for adenine at position $46(46 \mathrm{G} / \mathrm{A})$ that results in the amino acid substitution of glycine for arginine at position 16

Table 1. $\beta$-Adrenergic Receptor Genotypes in the Greek Population $(\mathrm{n}=99)$.

\begin{tabular}{|c|c|c|c|c|}
\hline Gene & Receptor & Nucleotide & Amino Acid & Frequency (\%) \\
\hline \multirow[t]{3}{*}{$A D R B 1$} & $\beta_{1}-\mathrm{AR}$ & $1165(C / C)$ & $389(\operatorname{Arg} / \operatorname{Arg})$ & 48 \\
\hline & & $1165(C / G)$ & $389(\mathrm{Arg} / G l y)$ & 41 \\
\hline & & $1165(G / G)$ & 389 (Gly/Gly) & 10 \\
\hline \multirow[t]{3}{*}{$A D R B 1$} & $\beta_{1}-\mathrm{AR}$ & $145(A / A)$ & $49(\mathrm{Ser} / \mathrm{Ser})$ & 80 \\
\hline & & $145(A / G)$ & 49 (Ser/Gly) & 16 \\
\hline & & $145(G / G)$ & $49($ Gly/Gly) & 3 \\
\hline \multirow[t]{3}{*}{$A D R B 2$} & $\beta_{2}-\mathrm{AR}$ & $46(G / G)$ & $16(G l y / G l y)$ & 39 \\
\hline & & $46(G / A)$ & 16 (Gly/Arg) & 48 \\
\hline & & $46(A / A)$ & $16(\mathrm{Arg} / \mathrm{Arg})$ & 12 \\
\hline \multirow[t]{3}{*}{$A D R B 2$} & $\beta_{2}-\mathrm{AR}$ & $79(C / C)$ & $27(G \ln / G \ln )$ & 44 \\
\hline & & $79(C / G)$ & $27(G \ln / G l u)$ & 47 \\
\hline & & $79(G / G)$ & $27(G l u / G l u)$ & 8 \\
\hline
\end{tabular}

$A D R B 1=$ adrenergic receptor $\beta_{1} ; \beta_{1}$-AR $=\beta_{1}$ adrenergic receptor; $A D R B 2=$ adrenergic receptor $\beta_{2} ; \beta_{2}$-AR $=\beta_{2}$ adrenergic receptor; $A$ = adenine; $C=$ cytosine; $G$ = guanine; $T$ = thymine; $A r g=$ arginine; $G l u$ = glutamic acid; $G l n=$ glutamine; $G l y=$ glycine; Ser=serine.
(16 Gly/Arg); the minor allele frequency for this polymorphism is $38 \%$ in the Greek population. This polymorphism does not alter the sensitivity of the $\beta_{2}$-receptor to acute adrenergic stimulation, but may facilitate the down-regulation of the receptor during chronic adrenergic stimulation $[2,3]$.

The second most common $\beta_{2}$-receptor polymorphism found in the Greek population is a substitution of cytosine for guanine at position $79(79 \mathrm{C} / G)$ that results in the amino acid substitution of glutamine for glutamic acid at position $27(27 \mathrm{Gln} / \mathrm{Glu})$; the minor allele frequency for this polymorphism is $32 \%$ in the Greek population. This polymorphism also does not alter the sensitivity of the $\beta_{2}$-receptor to acute adrenergic stimulation, but may facilitate the down-regulation of the recaptor during chronic adrenergic stimulation [2,3].

A rare third $\beta_{2}$-receptor polymorphism that has been previously reported, substitution of cytosine for thymine at position $491(491 C / T)$ that results in the amino acid substitution of threonine for isoleucine at position 164 (164 Thr/lle), was not seen in our population.

\section{DISCUSSION}

The present study is the first to report $\beta_{1}$ and $\beta_{2}$-adrenergic receptor polymorphisms in a healthy Greek population. The most common $\beta_{1}$ and $\beta_{2}$-adrenergic receptor polymorphisms in the Greek population are similar to Caucasian Europeans, and less common compared to African Americans suggesting some differences in ethnic groups [2]. Defining $\beta$-adrenergic receptor polymerphisms in clinical practice can potentially provide important information due to the variability in receptor response. Thus, $\beta$-adrenergic receptor polymorphisms might be taken into consideration when $\beta$-receptor stimulation or blockade therapies are used [1-5]. In addition, this information can be used to compare the frequency of $\beta$-adrenergic receptor polymorphisms in vari-

Table 2. Most Common $\beta$-Adrenergic Receptor Polymorphisms* .

\begin{tabular}{|c|c|c|c|c|c|c|}
\hline \multirow{2}{*}{ Gene } & \multirow{2}{*}{ Receptor } & \multirow{2}{*}{ Nucleotide Variability } & \multirow{2}{*}{ Amino Acid Variability } & \multicolumn{3}{|c|}{ Minor Allele Frequency (\%) } \\
\hline & & & & Greek & European & African American \\
\hline \multirow[t]{3}{*}{$A D R B 1$} & $\beta_{1}-\mathrm{AR}$ & $1165(C / G)$ & $389(\mathrm{Arg} / \mathrm{Gly})$ & 28 & 27 & 42 \\
\hline & & $145(A / G)$ & $49($ Ser/Gly) & 10 & 15 & 13 \\
\hline & & $1666(G / T)$ & $389(\mathrm{Arg} / \mathrm{Leu})$ & 0 & $<0.1$ & 0.9 \\
\hline \multirow[t]{3}{*}{$A D R B 2$} & $\beta_{2}-\mathrm{AR}$ & $46(G / A)$ & $16($ Gly/Arg $)$ & 38 & 41 & 50 \\
\hline & & $79(C / G)$ & $27(G \ln / G l u)$ & 32 & 42 & 27 \\
\hline & & $491(C / T)$ & $164($ Thr/lle) & 0 & $<4$ & $<4$ \\
\hline
\end{tabular}

$A D R B 1=$ adrenergic receptor $\beta_{1} ; \beta_{1}$-AR $=\beta_{1}$ adrenergic receptor; $A D R B 2=$ adrenergic receptor $\beta_{2} ; \beta_{2}$-AR $=\beta_{2}$ adrenergic receptor; $A=$ adenine; $C=$ cytosine; $G$ = guanine; $T$ = thymine; $A r g=$ arginine; $G l u=$ glutamic acid; $G l n=$ glutamine; $G l y=$ glycine; $L e u=$ leucine; $l l e=$ isoleucine; $S e r=$ serine; $T h r=$ threonine *Modified from Ref. 2. 
ous diseases (i.e. heritable diseases, arterial hypertension, coronary artery disease, other) to better tailor potential therapies. Interestingly, certain groups of patients (i.e. floppy mitral valve/mitral valve prolapse syndrome) have a greater response to isoproterenol, while elderly individuals may have decreased $\beta$-receptor function [8]. It should also be kept in mind that the response to intrinsic catecholamines during daily physical or other activities may be related to $\beta$-adrenergic receptor polymorphisms.

\subsection{Pharacogenetics-Pharmacogenomics}

Pharmacogenetics-pharmacogenomics is the field of biomedical sciences that studies the effect of pharmacologic agents in relation to genetic factors. A gene is comprised of DNA that encodes for a specific protein; a specific triplet of nucleotides in the DNA chain, called a codon, is translated into a specific amino acid. A polymorphism that involves a change in one nucleotide is called a single nucleotide polymorphism (SNP) [5]. Certain polymorphisms may be of clinical significance and may account for different responses to pharmacologic agents (pharmacogenetics). Often, however, the genetic contribution to the variability of drug response is not related to a polymorphism of one gene, but to multiple genes or to the entire genome (pharmacogenomics). Genetic factors may affect drug function by two major mechanisms: alteration of drug metabolism (pharmacokinetics), alteration of the sensitivity of enzymes or receptors via which pharmacologic agents provide their effect (pharmacodynamics), or both $[5,9,10]$.

Although pharmacogenetics-pharmacogenomics is a relatively new field in medical sciences, different responses to substances possibly related to genetic factors have been reported from antiquity. Pythagoras in the 6th century B.C. observed that eating fava beans was dangerous to certain individuals. For this reason, he recommended that everyone avoid fava beans $[5,11]$. Today it is known that serious hemolytic anemia may occur in individuals with a genetically determined deficiency of the anti-oxidant enzyme glucose-6-phosphate dehydrogenase (G6PD) after the consumption of fava beans [1].

\subsection{Pharmacogenetics and $\beta$-Adrenergic Receptors}

The response to $\beta$-adrenergic receptor stimulation or blockade may differ from person to person. This may be related to underlying disease, age, drug-drug interaction, and other factors; there are situations, however, where this difference cannot be explained with factors mentioned above [2,5]. Different responses from person to person may be related to polymorphisms.

Catecholamines endogenous or exogenous provide their effects via $\beta$-adrenergic receptors. The most common $\beta_{1}$ - receptor polymorphism found in the Greek population is $389 \mathrm{Arg} / \mathrm{Gly}$; this polymorphism is associated with a greater response to $\beta$-adrenergic stimulation in vitro and vivo. Studies have suggested that resting heart rate and blood pressure were greater in $389 \mathrm{Arg} / \mathrm{Gly}$ individuals compared to individuals without the polymorphism, and that these individuals were more responsive to $\beta$-blockers. Further, $389 \mathrm{Arg} / \mathrm{Gly}$ polymorphism underwent a greater degree of agonist related with desensitization (down-regulation) compared to those without the polymorphism. Thus, $389 \mathrm{Arg} / \mathrm{Gly}$ polymorphism has a greater capacity to undergo modification under conditions of elevated catecholamines [2-4]. On the other hand, $49 \mathrm{Ser} / \mathrm{Gly}$ polymorphism does not increase the sensitivity to acute $\beta$-adrenergic stimulation, but promotes down-regulation of the receptor during chronic stimulation. Thus, $\beta$-adrenergic receptor polymorphisms may alter the function of these receptors [2,12,13].

Medical therapy with $\beta$-blockers has been used for more than a half a century for the treatment of most cardiovascular diseases, such as acute myocardial infarction, chronic coronary artery disease, arterial hypertension, congestive heart failure, atrial fibrillation, aortic aneurysm-dissection, just to mention a few [1]. It has been suggested that the response to $\beta$-blockade therapy may be related to $\beta$-adrenergic receptor polymorphisms. Improvement in left ventricular ejection fraction or increased survival in patients with heart failure with $\beta$ blockade therapy was greater in those with the $389 \mathrm{Arg}$ / Gly polymorphism, although these findings were not confirmed in all studies. Studies also suggest that individuals with the $389 \mathrm{Arg} / \mathrm{Gly}$ polymorphism had a greater survival when treated with low dose $\beta$-blockade therapy compared to no therapy [2,14-16].

Several studies in Europe and in the United States of America demonstrated that $\beta$-blockade therapy in acute myocardial infarction may decrease infarct size, incidence of ventricular arrhythmias and mortality [17-23]; however, a more recent study in the Chinese population indicated that metoprolol administration in acute myocardial infarction may not be as beneficial due to an increase in cardiogenic shock [24]. The discrepancy in these results may be at least partially related to the various responses to $\beta$-blockade therapy in different ethnic groups [25].

Data suggest that in arterial hypertension, $\beta_{1}$-receptor polymorphisms influence the response and the outcome (blood pressure control and cardiovascular events) when $\beta$-blockade therapy was used; the greatest benefit was seen in patients with $389 \mathrm{Arg} / \mathrm{Gly}$ and $49 \mathrm{Ser} / \mathrm{Gly}$ polymorphisms, however, this was not recapitulated in all studies. Some of the discrepancies may be related to different $\beta$-blocking drugs that were used in these studies $[13,26]$. Similarly, in patients with atrial fibrillation the 
effect of $\beta$-blockade therapy was associated with $\beta$ adrenergic receptor polymorphism [27]. In patients with acute coronary syndromes, the outcome related to $\beta$ blockade therapy was also dependent on the $\beta_{1}$-receptor polymorphism; a greater benefit in survival was seen in individuals with $389 \mathrm{Arg} / \mathrm{Gly}$ and $49 \mathrm{Ser} / \mathrm{Gly}$ polymorphisms [28,29].

Stimulation of $\beta$-adrenergic receptors may have variable responses due to $\beta$-adrenergic receptor polymorphisms. Stimulation of $\beta_{1}$-receptors is used for the treatment of patients with acute heart failure and/or cardiogenic shock in which the effect may be related to receptor polymorphism. Further, $\beta_{2}$ agonists have been used for the treatment of chronic obstructive pulmonary disease and the effect may also be related to receptor polymorphism [1].

In conclusion, the most common $\beta_{1}$ and $\beta_{2}$-adrenergic receptor polymorphisms in the Greek population are similar to those of Caucasian European origin, and less common compared to African American origin indicating variability in ethnic groups [25]. Polymorphisms of $\beta$ adrenergic receptors may alter the response to $\beta$-adrenergic stimulation and blockade. Further, in certain diseases, such as congestive heart failure, arterial hypertension, atrial fibrillation, acute myocardial infarction and chronic coronary artery disease, patient outcomes when using $\beta$-blockade therapy may be related to receptor polymorphism. Better understanding of $\beta$-adrenergic receptor function will help to optimize therapy with $\beta$-blocking drugs and to improve patient outcomes. The data provide important information for the clinical application of pharmacogenetics related to $\beta$-adrenergic recaptors [30-32].

\section{AUTHOR CONTRIBUTION}

EKT, AAP, HB designed the research; EKT, BEG, TYL, TGK, AAP, $\mathrm{JAJ}$ and $\mathrm{HB}$ performed the research; KDB, JAJ and HB analyzed data; EKT, KDB, JAJ and HB wrote the manuscript.

\section{REFERENCES}

[1] Brunton, L.L. (2011) Goodman and Gilman's the pathophysiologic basis of therapeutics. 12th Edition, The McGraw-Hill Companies, Inc., New York.

[2] Johnson, J.A. and Liggett, S.B. (2011) Cardiovascular pharmacogenomics of adrenergic receptor signaling: Clinical implications and future directions. Clinical Pharmacology \& Therapeutics, $\mathbf{8 9}, 366-378$. doi:10.1038/clpt.2010.315

[3] Shin, J. and Johnson, J.A. (2007) Pharmacogenetics of beta-blockers. Pharmacotherapy, 27, 874-887. doi:10.1592/phco.27.6.874

[4] Johnson, J.A., Zineh, I., Puckett, B.J., McGorray, S.P., Yarandi, H.N. and Pauly, D.F. (2003) Beta1-adrenergic receptor polymorphisms and antihypertensive response to metoprolol. Clinical Pharmacology \& Therapeutics, 74, 44-52. doi:10.1016/S0009-9236(03)00068-7

[5] Stakos, D.A. and Boudoulas, H. (2002) Pharmacogenetics and pharmacogenomics in cardiology. The Hellenic Journal of Cardiology, 43, 1-15.

[6] Papatheodorou, A., Makrythanasis, P., Kaliakatsos, M., Dimakou, A., Orfanidou, D., Roussos, C., et al. (2010) Development of novel microarray methodology for the study of mutations in the SERPINA1 and ADRB2 genes-their association with obstructive pulmonary disease and disseminated bronchiectasis in Greek patients. Clinical Biochemistry, 43, 43-50.

doi:10.1016/j.clinbiochem.2009.08.026

[7] Shin, J., Lobmeyer, M.T., Gong, Y., Zineh, I., Langaee, T.Y., Yarandi, H., et al. (2007) Relation of beta(2)-adrenoceptor haplotype to risk of death and heart transplantation in patients with heart failure. American Journal of Cardiology, 99, 250-255. doi:10.1016/j.amjcard.2006.08.020

[8] Boudoulas, H., Reynolds, J.C., Mazzaferri, E. and Wooley, C.F. (1983) Mitral valve prolapse syndrome: The effect of adrenergic stimulation. Journal of the American College of Cardiology, 2, 638-644. doi:10.1016/S0735-1097(83)80303-9

[9] Voora, D. and Ginsburg, G.S. (2012) Clinical application of cardiovascular pharmacogenetics. Journal of the American College of Cardiology, 60, 9-20. doi:10.1016/j.jacc.2012.01.067

[10] Salari, K., Watkins, H. and Ashley, E.A. (2012) Personalized medicine: Hope or hype? The European Heart Journal, 33, 1564-1570. doi:10.1093/eurheartj/ehs112

[11] Diogenis Laertios, "Pythagoras," Vitae Philosophoru VIII, 8.33.6- 8.34.6.

[12] Humma, L.M., Puckett, B.J., Richasdson, H.E., Terra, S.G., Andrisin, T.E., Lejeune, B.L., et al. (2001) Effects of beta1-adrenergic polymorphisms on resting hemodynamics in patients undergoing diagnostic testing for ischemia. American Journal of Cardiology, 88, 1034-1037. doi:10.1016/S0002-9149(01)01986-5

[13] Peng, Y., Xue, H., Luo, L., Yao, W. and Li, R. (2009) Polymorphisms of the adrenergic receptor gene are associated with essential hypertension in Chinese. Clinical Chemistry and Laboratory Medicine, 47, 1227-1231. doi:10.1515/CCLM.2009.276

[14] Kaye, D.M., Smirk, B., Williams, C., Jennings, G., Esler, M. and Holst, D. (2003) Beta-adrenoreceptor genotype influences the response to carvedilol in patients with congestive heart failure. Pharmacogenetics, 13, 379-382. doi:10.1097/00008571-200307000-00002

[15] Borjesson, M., Magnusson, Y., Hjalmarson, A. and Anderson, B. (2000) A novel polymorphism in the gene coding for the beta 1-adrenergic receptor is associated with survival in patients with heart failure. The European Heart Journal, 21, 1853-1858. doi:10.1053/euhj.1999.1994

[16] Biolo, A., Clausell, N., Santos, K.G., Salvaro, R., AshtonProlla, P., Borges, A., et al. (2008) Impact of beta1-adrenergic receptor polymorphisms on susceptibility to heart failure, arrhythmogenesis, prognosis, and response to betablocker therapy. American Journal of Cardiology, 102, 
726-732. doi:10.1016/j.amjcard.2008.04.070

[17] Rydén, L., Ariniego, R., Arnman, K., Herlitz, J., Hjalmarson, A., Holmberg, S., et al. (1983) A double-blind trial of metoprolol in acute myocardial infarction. Effects on ventricular tachyarrhythmias. The New England Journal of Medicine, 308, 614-618. doi:10.1056/NEJM198303173081102

[18] Roqué, F., Amuchastegui, L.M., Lopez Morillos, M.A., Mon, G.A., Girotti, A.L., Drajer, S., et al. (1987) Beneficial effects of timolol on infarct size and late ventricular tachycardia in patients with acute myocardial infarction. Circulation, 76, 610-617. doi:10.1161/01.CIR.76.3.610

[19] Boudoulas, H. (1990) Therapeutic interventions which may improve survival in patients with coronary artery disease. Acta Cardiologica, 45, 477-487.

[20] The MIAMI Trial Research Group (1985) Metoprolol in acute myocardial infarction (MIAMI). A randomised placebo-controlled international trial. The European Heart Journal, 6, 199-226.

[21] Hjalmarson, A., Elmfeldt, D., Herlitz, J., Holmberg, S., Málek, I., Nyberg, G., et al. (1981) Effect on mortality of metoprolol in acute myocardial infarction. A double-blind randomised trial. Lancet, 2, 823-827. doi:10.1016/S0140-6736(81)91101-6

[22] Hjalmarson, A., Herlitz, J., Holmberg, S., Rydén, L., Swedberg, K., Vedin, A., et al. (1983) The Göteborg metoprolol trial. Effects on mortality and morbidity in acute myocardial infarction. Circulation, 67, I26-I32.

[23] Hjalmarson, A. and Olsson, G. (1991) Myocardial infarction. Effects of beta-blockade. Circulation, 84, VI101VI107.

[24] Chen, Z.M., Pan, H.C., Chen, Y.P., Peto, R., Collins, R., Jiang, L.X., et al. (2005) COMMIT (ClOpidogrel and Metoprolol in Myocardial Infarction Trial) collaborative group. Early intravenous then oral metoprolol in 45,852 patients with acute myocardial infarction: Randomised placebo-controlled trial. Lancet, 366, 1622-1632. doi:10.1016/S0140-6736(05)67661-1

[25] Johnson, J.A. (2008) Ethnic differences in cardiovascular drug response: Potential contribution of pharmacogenetics. Circulation, 23, 1383-1393. doi:10.1161/CIRCULATIONAHA.107.704023

[26] Suonsyrja, T., Donner, K., Hannila-Handelberg, T., Fodstad, H., Kontula, K. and Hiltunen, T.P. (2010) Common genetic variation of beta1- and beta2-adrenergic receptor and response to four classes of antihypertensive treatment. Pharmacogenetics and Genomics, 20, 342-345. doi:10.1097/FPC.0b013e328338e1b8

[27] Parvez, B., Chopra, N., Rowan, S., Vaglio, J.C., Muhammad, R., Roden, D.M., et al. (2012) A common 1-adrenergic receptor polymorphism predicts favorable response to rate-control therapy in atrial fibrillation. Journal of the American College of Cardiology, 59, 49-56. doi:10.1016/j.jacc.2011.08.061

[28] Cresci, S., Dorn II, G.W., Jones, P.G., Beitelshees, A.L., Li, A.Y., Lenzini, P.A., et al. (2012) Adrenergic-pathway gene influence beta-blocker-related outcomes after acute coronary syndrome in a race-specific manner. Journal of the American College of Cardiology, 60, 898-907. doi:10.1016/j.jacc.2012.02.051

[29] Puri, R., Liew, G.Y.H., Nicholls, S.J., Nelson, A.J., Leong, D.P., Carbone, A., et al. (2012) Coronary 2-adrenoreceptors mediate endothelium-dependent vasoreactivity in humans: Novel insights from an in vivo intravascular ultrasound study. The European Heart Journal, 33, 495-504. doi:10.1093/eurheartj/ehr359

[30] Evans, W.E. and Relling, M.V. (1999) Pharmacogenetics: Translating functional genomics into rational therapeutics. Science, 286, 487-91. doi:10.1126/science.286.5439.487

[31] Wachter, S.B. and Gilbert, E.M. (2012) Beta-adrenergic receptors, from their discovery and characterization through their manipulation to beneficial clinical application. Cardiology, 122, 104-112. doi:10.1159/000339271

[32] Roden, D.M., Altman, R.B., Benowitz, N.L., et al. (2006) Pharmacogenomics: Challenges and opportunities. Annals of Internal Medicine, 145, 749-757. doi:10.7326/0003-4819-145-10-200611210-00007 